\title{
Spontaneous fits after convulsions with fever
}

\author{
SHEILA J. WALLACE \\ From the Department of Child Life and Health, University of Edinburgh
}

SUMMARY 112 of an original sample of 134 children with febrile convulsions were reviewed between 8 years and 9 years 10 months after their initial attack. $17 \%$ of those followed up had had at least one spontaneous fit. A significant correlation was found with perinatal abnormalities. $12 \%$ had continuing recurrent fits. Persisting grand mal occurred most commonly in lower social class children who had had perinatal abnormalities and continued to have long-term neurological disorders. Psychomotor epilepsy correlated significantly with a prolonged or repeated initial convulsion with unilateral features. It is suggested that the development of grand mal and temporal lobe epilepsies after convulsions with fever are determined by different mechanisms.

A spontaneous fit is defined here as any fit occurring in the absence of fever. Epilepsy is diagnosed if such fits were recurrent. A review of previous publications on the risks for epilepsy in children who have convulsed with fever gives figures varying from 1 to 93\% (Lennox-Buchthal, 1973). In an attempt to further identify factors which might influence the later outcome, this study reports the incidence and types of seizure suffered by 112 children between 8 years and 9 years 10 months after an initial attack with fever.

\section{Patients and methods}

134 consecutive admissions for convulsions with fever were seen at the Royal Hospital for Sick Children, Edinburgh, between December 1964 and August 1966. All were aged more than 2 months and less than 7 years at the initial fit. Apart from admission to hospital, no other selection of patients was made. It was possible to trace 112 of the 134 children between July and October 1974. 69 boys and 43 girls were reviewed. 103 children and their parents or guardians were interviewed personally, a parent was seen or spoken to on the telephone in 4 cases, letters with proformata enclosed were returned by 4 parents and, in 1 case, by the Edinburgh Social Services Department. The children reviewed were comparable for sex, social class, perinatal abnormality, earlier neurological disorder, and age at the first fit with those of the original sample who were not traced. A significant excess of children whose initial fit was prolonged, unilateral,

Received 23 June 1976 or repeated within the same illness was present among those reviewed $\left(\chi^{2}=7 \cdot 23, \mathrm{P}<0 \cdot 01\right)$. The ages at follow-up ranged from 8 years 9 months to 14 years 9 months, mean 10 years 11 months.

Four aspects of fits occurring in the absence of fever were examined. These are the incidence of any type of convulsion occurring at any time when afebrile, that of epilepsy continuing to the time of review, the precursors of grand mal epilepsy, and those of psychomotor epilepsy.

The influence of the following factors was assessed: sex; social class: either I, II, IIIA (nonmanual) or IIIB, IV, V (manual); convulsive disorders of any sort in parents or sibs; perinatal abnormality-taken as those abnormalities found significantly more often when the same group of patients was compared with their sibs (Wallace, 1972); persisting neurological disorder-for the 9 children where information but not examination was obtained in 1974, the neurological status when last seen, always at least 18 months from the initial convulsion, was used to categorize; age at first fit-either less than 19 months, or 19 months or more; type of initial fit-either simple, i.e. completely generalized, single, and of less than $\mathbf{3 0}$ minutes' duration, or complicated, i.e. all other convulsive episodes; recurrent convulsions with fever-either single episode; 2 or 3 episodes; or, more than 3 episodes; electroencephalographic (EEG) findingsspike or spike-wave complexes either absent, or present within 7 days, or present within 36 months of initial convulsion.

The data for each factor and its influence on the aspect of the fits under investigation were submitted 
to the $\chi^{2}$ test of significance. Correction was made for other factors if these appeared to be relevant.

\section{Results}

The total number of patients with each factor investigated and the number of patients with each type of spontaneous fit are shown in the Table.

At least one convulsion when afebrile. 19 (10 males, 9 females) of the 112 children had had at least one convulsion when afebrile. 11 of the 19 had grand mal attacks only, 2 grand mal and psychomotor fits, 1 grand mal and myoclonic epilepsy, and 5 psychomotor attacks only. Compared with the 93 children who had no attacks when afebrile, and after correction for sex, social class, and family history, those 19 who later had fits without fever were significantly likely to have suffered a perinatal abnormality $\left(\chi^{2}=3 \cdot 97, \mathrm{P}<0.05\right)$. Children from the nonmanual social classes whose first fit occurred at 19 months or more had an increased incidence of later convulsions when afebrile, but the numbers were too small for statistical analysis. After correction for sex, social class, family history, perinatal and neurological disorders, spikes or spike-wave complexes on the EEG within 36 months of the initial convulsion correlated significantly with later fits when afebrile $\left(x^{2}=9 \cdot 0, \mathrm{P}<0 \cdot 005\right)$.

Epilepsy continuing to the time of review. $14(12 \%)$ children ( 9 males, 5 females) had recurrent convulsive episodes within the 12 months preceding followup. Children who had epilepsy of any type between 8 years and 9 years 10 months after their first convulsion with fever were likely to have come from the lower social classes, to have suffered a perinatal abnormality, to have continuing neurological abnormality, to have had more than one convulsion when afebrile, and had spikes or spike-wave complexes on their EEGs within 36 months of their initial fit. However, after correction for other factors which might influence outcome, only in the case of the EEG results were the findings significant for a single factor. Compared with $\mathbf{2 5}$ of the $\mathbf{9 8}$ children without epilepsy, 9 of the 14 with epilepsy had spikes or spike-wave complexes within $\mathbf{3 6}$ months of their initial fit $\left(x^{2} 5 \cdot 01, P<0 \cdot 05\right.$, Yates's correction). Examination of the cumulative effects of separate factors showed that those males who were of lower social class, with a positive family history for convulsive disorders, who had had a perinatal abnormality, and were neurologically abnormal were most likely to be suffering from epilepsy. 5 out of 14 males with these characteristics were epileptic compared with 4 of 55 other males. For the females, the group most at risk for epilepsy were those from the lower social classes, with a negative family history, who had had a perinatal abnormality and continued to have abnormal neurological signs. 4 of the 9 girls with these characteristics were epileptic compared with 1 of 34 others.

Grand mal with or without other epilepsies. 10 children (6 males, 4 females) were still having attacks of grand mal when reviewed. Compared with other males those from the lower social classes with a positive family history and perinatal and neurological abnormalities had an increased risk of having grand mal epilepsy between 8 years and 9 years 10 months from their initial convulsion with fever. The 4 females with grand mal epilepsy were concentrated among those of lower social class, with a negative family history and a perinatal abnormality.

Table Frequency of factors investigated in all 112 children and in each group of patients with spontaneous fits

\begin{tabular}{|c|c|c|c|c|c|}
\hline Factor & $\begin{array}{l}\text { All } \\
\text { children } \\
\text { reviewed }\end{array}$ & $\begin{array}{l}\text { Fits at any } \\
\text { time when } \\
\text { afebrile }\end{array}$ & $\begin{array}{l}\text { Any type } \\
\text { of epilepsy } \\
\text { at review }\end{array}$ & $\begin{array}{l}\text { Grand mal } \\
\text { epilepsy } \\
\text { at review }\end{array}$ & $\begin{array}{l}\text { Psychomotor } \\
\text { fits at } \\
\text { any time }\end{array}$ \\
\hline Male & 69 & 10 & 5 & 6 & 5 \\
\hline Female & 43 & 9 & 9 & 4 & 2 \\
\hline \multicolumn{6}{|l|}{ Social class } \\
\hline I, II, IIIA (nonmanual), & 40 & 7 & 3 & 1 & 2 \\
\hline Family history: positive (sibs \pm parents) & 44 & 9 & 6 & 4 & 4 \\
\hline Perinatal abnormality present & 70 & 16 & 12 & 9 & 6 \\
\hline Persisting neurological disorder & 79 & 17 & 12 & 9 & 6 \\
\hline Age at first fit $:<19 \mathrm{~m}$ & 55 & 7 & 7 & 8 & 4 \\
\hline \multicolumn{6}{|l|}{ Complicated initial fit (prolonged, repeated, generalized } \\
\hline fits and any fit with focal features) & 75 & 12 & 9 & 5 & 5 \\
\hline Prolonged or repeated initial fit with unilateral features & 26 & 6 & 5 & 2 & 5 \\
\hline$>1$ episode of convulsions with fever & 51 & 10 & 8 & 6 & 5 \\
\hline$>3$ episodes of convulsions with fever & 17 & 6 & 4 & 2 & 3 \\
\hline Total no. of patients in each group & 112 & 19 & 14 & 10 & 7 \\
\hline
\end{tabular}


Psychomotor epilepsy. Psychomotor epilepsy was diagnosed only in the presence of typical clinical attacks, but all 7 children involved had on at least one occasion focal temporal lobe abnormalities on their EEGs. 5 males and 2 females $(6 \%$ of the 112 children) had suffered psychomotor fits at some time. 3 males and 1 female were still affected at the time of review. Of the 3 who had previously had psychomotor fits, 2 continued to have grand mal and one was reported completely well, without therapy, for 3 years. For the 5 males who, at any time, had psychomotor attacks, social class appeared to be irrelevant. 4 had a positive family history and had suffered perinatal abnormalities. 3 of these 4 and the boy who was negative for family history and perinatal factors had had a prolonged or repeated initial convulsion with unilateral features. 2 of the 5 had only ever had one major fit. Both females were of lower social class, family history negative, and had perinatal and neurological disorders. One had had a prolonged unilateral convulsion. In all, 5 of the 7 with psychomotor epilepsy and 21 of the other 105 children had had such a convulsion. The correlation between a severe initial fit with unilateral features and the later development of temporal lobe epilepsy is significant $\left(\chi^{2} 6.26, \mathrm{P}<0.02\right.$, Yates's correction). Though all but one child had had a perinatal abnormality, this factor did not correlate significantly with later psychomotor epilepsy.

The determinants of later grand mal epilepsy therefore appear to be those associated with low social class and its accompaniments, whereas psychomotor fits follow a prolonged unilateral convulsion regardless of social class.

\section{Discussion}

There is general agreement that the risk for spontaneous fits is greater for children who have convulsed when feverish than for the general population (Faerber, 1929; Herlitz, 1941; Livingston et al., 1947; Debre et al., 1948; Zellweger, 1948; Lennox, 1949, 1953; Ekholm and Niemineva, 1950; Friderichsen and Melchior, 1954; Melin, 1954; Cary, 1956; Hrbek, 1957; Laplane et al., 1958; Bamberger and Matthes, 1959; Horstmann and Schinnerling, 1963; Doose et al., 1966; Degen and Goller, 1967; Millichap, 1968; Van den Berg and Yerushalmy, 1969; Frantzen et al., 1970).

However, variable prognoses have been given and these are inevitably dependent on the selection of material. In a population survey of 18500 children it was found that of the 246 who had convulsed when febrile $3 \%$ later had spontaneous attacks (Van den Berg and Yerushalmy, 1969). The higher incidence, $19 \%$, given by the present study might be explained by selection by admission to hospital, or by the higher percentage of complicated initial convulsions among those reviewed. Therefore the outlook for spontaneous seizures in an unselected population cannot be extrapolated from this group. However, it is possible to draw conclusions for children with specific characteristics.

Most previous reports have concentrated on the consideration of each adverse factor separately. They have also tended to assume that all types of spontaneous fit will be preceded by the same circumstances. With the exceptions of the increased incidence of perinatal abnormalities in those children who had at least one fit when afebrile, the greater risk of later psychomotor epilepsy in those whose initial fit had been unilateral and prolonged or repeated, and the EEG findings in persisting epilepsy, single factors were not found to be of significant importance in prognosis in the present study. In addition, less than half of the children with any single significant adverse factor were likely to have spontaneous attacks (Table). Alternatively, combinations of some features made the likelihood of such fits very high.

Although there was a trend towards spontaneous grand mal in children who were from the lower social classes, the presence of additional factors seemed to be necessary for epilepsy to become established. Lower social class mothers are known to have an increased incidence of perinatal abnormalities (Butler and Bonham, 1963). But even in the absence of such abnormality, their children have a poorer outlook for subsequent intellectual development (Drillien, 1968). Since convulsions must also be considered symptoms of cerebral disorder, it is perhaps not surprising that they too may be dependent for their persistence on factors related to the socioeconomic status, a finding already considered by Miller et al. (1974). However, it may not be possible to consider the socioeconomic status in isolation from the family history. A father with epilepsy can lower the social class because of his job opportunities.

In addition, the influence of the family history may not be separable from perinatal abnormality. Frantzen et al. (1970) reported that a family history positive for epilepsy was significantly correlated with perinatal abnormalities. The present group showed a similar, but nonsignificant, trend. Anatomical neurological changes which could lower the convulsive threshold might also be to some extent inherited. Bamberger and Matthes (1959) found that where the initial fit lasted less than 30 minutes, a family history positive for epilepsy worsened the prognosis and that if brain damage was also present the likelihood of subsequent epilepsy was even higher. In 
the present study the effects of a positive family history appeared to be different in males and females. The presence of either parents or sibs with fits appeared additive to social class, perinatal abnormality, and neurological disorder in males who later had grand mal epilepsy, whereas it was either noncontributory or protective in females. Where the influence of family history on outcome has previously been explored for the sexes separately, the males with a positive family history had the best prognosis (Taylor and Ounsted, 1971). That study contained a much larger proportion of young girls who had severe convulsions with serious sequelae than the present group, and this may have outweighed the boys with a positive family history.

Taylor and Ounsted (1971) also emphasize the importance of considering other adverse factors for the sexes separately and highlight the vulnerability of girls under one year of age. In the present study children of either sex whose convulsive illness started in the first 12 months did not appear more likely to have later epilepsy, but the number was very small. In contrast, in the higher social classes children whose first fit occurred at 19 months or older were at increased risk of having at least one convulsion when afebrile. It is postulated that the first convulsion was precipitated later in these children since they were less likely to contract infections in the earlier months, but that conditions for spontaneous attacks had already been satisfied. However, though these children were likely to have one convulsion when afebrile, they were not likely to suffer from grand mal epilepsy 8 to 9 years after their initial fit with fever.

Recurrence of convulsions with fever is dependent on the age of onset, sex, family history, neurological findings, and type of initial fit (Wallace, 1974). The effect of such recurrences on the development of epilepsy therefore cannot be considered in isolation from these factors. It is possible that where subsequent epilepsy has been related to the number of previous attacks with fever (Bamberger and Matthes, 1959; Horstmann and Schinnerling, 1963), a record was being kept of a continuing propensity to convulse despite increasing age, with age merely altering the circumstances under which the convulsions occur.

The children in the present study who later developed psychomotor epilepsy suffered from a significant excess of initial convulsions which were severe and unilateral. This agrees with the findings of Ounsted et al. (1966). However, a predisposition to a complicated initial convulsion has been related to sex, age at onset, perinatal abnormalities, family history, and preceding neurological disorder (Wallace, 1975). It is possible, therefore, that many children who develop psychomotor epilepsy are pro- grammed for a severe initial fit, given the necessary febrile stimulus during the vulnerable age period. Nevertheless, this group of patients appears to be the most readily amenable to the prevention of later epilepsy. A prolonged convulsion is known to cause damage to the $\mathbf{H}_{1}$ (Sommer) sector of the temporal lobe in animals with no known preceding brain abnormality (Meldrum and Brierley, 1973). Prevention of psychomotor epilepsy almost certainly lies in prevention of prolonged fits.

In conclusion, the persistence of grand mal epilepsy to between 8 years and 9 years 10 months after an initial convulsion with fever is largely determined by events preceding the initial fit. Psychomotor epilepsy is significantly related to a prolonged or repeated convulsion with unilateral features and might be preventable by enthusiastic treatment of the initial fit.

Thanks are due to the children and parents for their co-operation, and to all the paediatricians at The Royal Hospital for Sick Children, Edinburgh, for allowing their patients to be examined; to Dr T. T.S. Ingram for continuous support and encouragement; to Professor J. O. Forfar who allowed the follow-up study to be conducted in the Department of Child Life and Health, University of Edinburgh. This review was made possible through the generosity of the Scottish Council for the Care of Spastics. Organizational and secretarial help were received from Mrs. M. Johnson, Mrs V. Macmillan, and Mrs D. Dupres.

\section{References}

Bamberger, P., and Matthes, A. (1959). Anfälle im Kindesalter, p. 422. Karger, Basel.

Butler, N. R., and Bonham, D. G. (1963). Perinatal Mortality, p. 24. Livingstone, London.

Cary, W. (1956). Febrile convulsions in infancy and childhood. Medical Journal of Australia, 2, 254-256.

Debre, R., Thieffry, S., Neyroud, M., and Lerique, A. (1948). Les convulsions hyperpyrétiques. Archives Françaises de Pédiatrie, 5, 62-65.

Degen, R., and Goller, K. (1967). Die sogenannten Fieberkrämpfe des Kindesalters und ihre Beziehungen zur Epilepsie. Nervenarzt, 38, 55-61.

Doose, H., Petersen, C. E., Völzke, E., and Herzberger, E. (1966). Fieberkrämpfe und Epilepsie. I. Ätiologie, klinisches Bild und Verlauf der sogenannten Infekt-oder Fieberkrämpfe. Archiv für Psychiatrie und Zeitschrift f.d. ges. Neurologie, 208, 400-412.

Drillien, C. M. (1968). Studies in mental handicap. Archives of Disease in Childhood, 43, 283-294.

Ekholm, E., and Niemineva, K. (1950). On convulsions in early childhood and their prognosis. Acta Paediatrica, 39, 481-501.

Faerber, E. (1929). Klinische Beobachtungen über die Initialkrämpfe im Kindesalter. Jahrbuch für Kinderheilkunde, 124, 148-158. 
Frantzen, E., Lennox-Buchthal, M., Nygaard, A., and Stene, J. (1970). A genetic study of febrile convulsions. Neurology, 20, 909-917.

Friderichsen, C., and Melchior, J. (1954). Febrile convulsions in children: frequency and prognosis. Acta Paediatrica, 43, Suppl. 100, 307-317.

Herlitz, G. (1941). Studien über die sogenannten initialen Fieberkrämpfe bei Kindern. Acta Paediatrica, 29, Suppl. 1, 106.

Horstmann, W., and Schinnerling, W. (1963). Zur prognose der sogenannten Fieberkrämpfe. Monatsschrift für Kinderheilkunde, 111, 52-57.

Hrbek, A. (1957). Fieberkrämpfe im Kindesalter. Annales Paediatrici, 188, 162-182.

Laplane, R., Humbert, R., Laget, P., Salbreux, R., and Debray, P. (1958). Suites immédiates et lointaines des convulsions fébriles avant quatre ans. Revue Neurologique, 99, 26-38.

Lennox, M. A. (1949). Febrile convulsions in childhood: a clinical and electroencephalographic study. American Journal of Diseases of Children, 78, 868-882.

Lennox, W. G. (1953). Significance of febrile convulsions. Pediatrics, 11, 341-356.

Lennox-Buchthal, M. A. (1973). Febrile Convulsions: a Reappraisal, p. 94. Elsevier, Amsterdam.

Livingston, S., Bridge, E. M., and Kajdi, L. (1947). Febrile convulsions: a clinical study with special reference to heredity and prognosis. Journal of Pediatrics, 31, 509-512.

Meldrum, B. S., and Brierley, J. B. (1973). Prolonged epileptic siezures in primates. Archives of Neurology, 28, 10-17.
Melin, K. A. (1954). Zur Prognose der Infektkrämpfe. Monatsschrift für Kinderheilkunde, 102, 62-63.

Miller, F. J. W., Court, S. D. M., Knox, E. G., and Brandon, S. (1974). The School Years in Newcastle upon Tyne 1952-1962, p. 134. Oxford University Press, London.

Millichap, J. G. (1968). Febrile Convulsions. Macmillan, New York.

Ounsted, C., Lindsay, J., and Norman, R. (1966). Biological Factors in Temporal Lobe Epilepsy. Clinics in Developmental Medicine 22. Heinemann, London.

Taylor, D. C., and Ounsted, C. (1971). Biological mechannisms influencing the outcome of seizures in response to fever. Epilepsia, 12, 33-45.

Van den Berg, B. J., and Yerushalmy, J. (1969). Studies on convulsive disorders in young children. Pediatric Research, 3, 298-304.

Wallace, S. J. (1972). Aetiological aspects of febrile convulsions. Archives of Disease in Childhood, 47, 171-178.

Wallace, S. J. (1974). Recurrence of febrile convulsions. Archives of Disease in Childhood, 49, 763-765.

Wallace, S. J. (1975). Factors predisposing to a complicated initial febrile convulsion. Archives of Disease in Childhood, 50, 943-947.

Zellweger, H. (1948). Krämpfe in Kindesalter. Helvetica Paediatrica Acta, 3, Suppl. 5, 58-140.

Correspondence to Dr. S. J. Wallace, Department of Child Health, University Hospital of Wales, Heath Park, Cardiff CF4 4XN. 